\title{
CONSTRUCTABIIITY AND AUTOMATION
}

\author{
Richard Tucker \\ Director, The Construction Industry Institute \\ The University of Texas at Austin
}

\begin{abstract}
This paper discusses the goals and major components of Constructability. Results from several projects that had formal constructability programs are reviewed. The link between constructability and automation is examined.
\end{abstract}

\section{Introduction}

Constructability and automation share the same the goal-to offset a shortage of workers through working smarter. Japan is already experiencing a shortage of workers and we in the United states expect one soon. Europe, on the other hand, may have won a brief reprieve as the result of communism's collapse, but will need to adopt strategies to deal with worker shortages at some point in the future. The reason for current and impending worker shortages is that construction has several fundamental problems that often cause new entrants to the workforce to consider other industries first and construction last.

The Japanese succinctly sum up these problems with five "K" words:

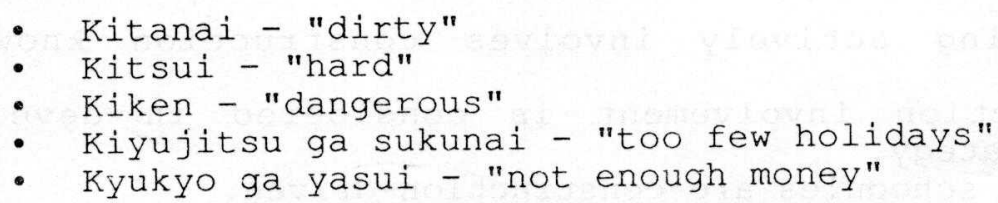

Constructability and automation, considered separately, approach each of these traditional problems differently. Constructability seeks to work within currently available technologies; automation seeks to create new technologies. However, constructability, as we shall later see, is an important consideration in design for automated construction.

\section{what is constructability?}

Constructability is the optimum use of construction knowledge and experience in planning, design, procurement, and field operations to achieve overall project objectives [1]. Project objectives will vary among projects but each project will have objectives related to schedule, safety, quality, and cost. As Figure 1 shows, involving those with construction knowledge and experience from the very outset promises the greatest rewards with respect to cost. Early involvement of those with construction knowledge and experience can also have a dramatic effect on the safety, quality, and schedule objectives. 


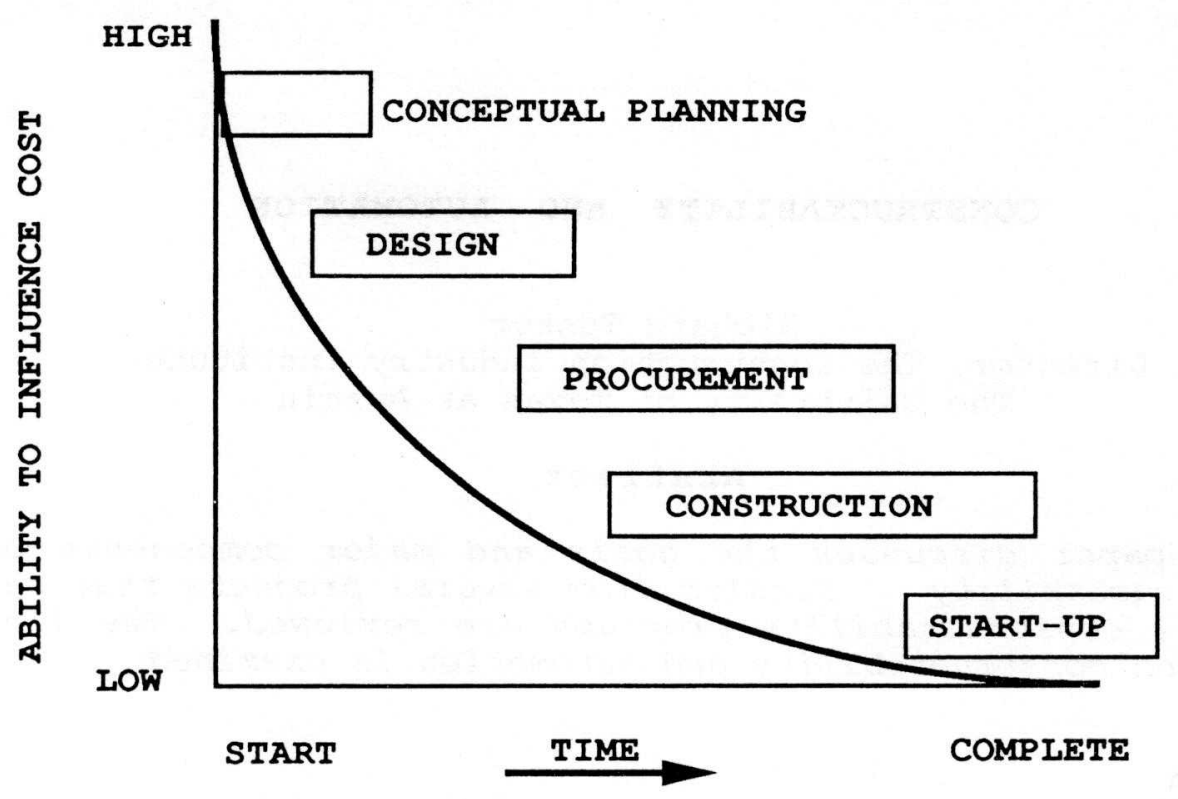

Figure 1. Cost Influence Curve

To assure good results from a constructability program, a total of fourteen concepts covering conceptual planning, design and procurement, and construction have been identified [1]:

Conceptual Planning Phase

1. Constructability programs are made an integral part of project execution plans.

2. Project planning actively involves construction knowledge and experience.

3. Early construction involvement is considered in development of contracting strategy.

4. Overall project schedules are construction-driven.

5. Basic design approaches consider major construction methods.

6. Site layouts promote efficient construction as well as efficient operation and maintenance.

\section{Design and Procurement Phase}

7. Design and procurement schedules are construction-driven.

8. Designs are configured to enable efficient construction.

9. Design elements are standardized.

10. Construction efficiency is considered in specification development.

11. Module/preassembly designs are prepared to facilitate fabrication, transport, and installation.

12. Designs promote construction accessibility of personnel, material, and equipment.

13. Designs facilitate construction under adverse weather conditions.

Construction Phase

14. Constructability is enhanced when innovative construction methods are utilized. 
The fourteen concepts, when reviewed, are just good common sense. During the heat of project execution, however, common sense can easily fall prey to expediency unless management insists on and has a plan for assuring adherence to these principles. Recently four companies, one owner and three contractors, in a partnering arrangement have extended the concepts listed above to a process-detailed in two volumes-for everyday application on real projects [2]. They call this program IPEC (eye-peck) for Integrated Procurement, Engineering, and Construction in an attempt to obtain greater acceptance by all the parties. The process describes lessons learned by discipline; such as civil, electrical, and mechanical; and all the details needed to administer the program, from how the constructability team is organized to recognition and awards for superior achievement.

\section{Constructability In Action}

How do the constructability concepts help us tackle the "K" words? The answer to this question is best demonstrated with examples.

The first example is taken from a chemical plant recently built in Houston [3]. The Owner, Engineer, and Contractor decided to eliminate or minimize worker exposure to falls, which are responsible for 33 percent of construction fatalities. They adopted a two-step approach: first, they would eliminate fall hazards where possible during design, and second, they would insist on state-of-the-art equipment where they could not eliminate fall exposure.

Structural components, including a stair tower that rose over 135 feet, were designed for horizontal assembly, which means that stresses induced by lifting the completed structures to its vertical position had to be taken into account. The structures assembled at ground level included all ladders, stairs, platforms, and tie-off lines so that workers were afforded maximum protection during subsequent work on the installed structure. Connections were designed at chest height to promote better safety, productivity, and quality. A similar process was followed for process towers, which were assembled on the ground and then raised into place only after all safety features and most of the operating components had been installed.

The project used 1.3 million worker hours to erect 2400 tons of structural steel and to install over 130,000 feet of pipe. Yet the project suffered no lost time accidents, and it had only six osHA recordable injuries for a total recordable rate of about 1.0 . Compare this with the national average of over 13.0 for all construction. While investigating safety needs for construction workers, the project team found that maintenance and operations workers have many of the same needs. A plant that has construction safety designed in has made maintenance and operations safer too.

The second example is taken from a refinery recently expanded in the United Kingdom [4]. The area where the refinery is located has poor access by road, no rail line in the immediate vicinity, a limited local workforce, and suffers short, cold, and wet days during the winter. To complicate the workforce problem, another of the plant's units was scheduled for renovation during construction of the new unit. On the plus side, the site does have good access to the sea, an important feature for shipment of crude oil to the refinery and refined products to the market.

To overcome site related problems and to reduce weather- and laborrelated risks, the project team elected to pursue a modular construction strategy. They decided to award a single contract for loading, transport, and heavy lift of the module. This contractor became a member of the project team and helped determine site layout. The contractor also advised the design team on module size and features needed to overcome erection 
conflicts, a restricted loading and unloading schedule, and the steep climb from the dock to the site.

By proceeding with module construction while the site work was still under way, the project was completed four months sooner than would have been possible with conventional construction. Moreover, the quality of modules constructed in the fabrication yard was higher than that typically obtained on-site, and the workers were more productive as well. Although project cost was about one million dollars above that estimated for conventional construction, the owner's additional income from earlier start-up more than offset the added cost.

Both of these projects used constructability to make the work safer and less strenuous. The second project, through modularization, may have made the work cleaner overall by fabricating modules in a yard.

But does a constructability program have quantifiable benefits beyond successfully assaulting the " $K$ " words? CII's Constructability Task Force recently undertook this question and has determined that the answer is yes. A case study involving a chemical plant in Louisiana showed that a formal constructability program, which increased total project cost by 0.11 percent, produced an estimated savings of 1.1 percent of total project cost [5]. This translates into a 10:1 return. The estimated savings are based only upon documented ideas and readily quantifiable results; although the project team implemented a total of 327 documented constructability ideas, only 83 were considered quantifiable. The project team believes that the actual return was much higher and points to a ten percent reduction in project duration and a zero lost-time-accident safety record as evidence. The benefits obtained from early input on construction sequencing, procurement strategies, and improved coordination can be elusive, but undoubtedly contribute to superior performance.

\section{Constructability and Automation}

If automation includes equipment to automate the storage, retrieval, and manipulation of information, ther both projects discussed above, and indeed many projects, already rely on automation. CADD was used extensively on both projects. Without CADD, the project teams would have found the number of site layouts they could consider to promote efficient and safe construction significantly reduced. Careful consideration of site layout in the conceptual planning phase is an essential part of constructability. Without computerized engineering calculation, the additional engineering needed to consider stresses generated when raising horizontally assembled elements, or the stresses generated during sea transport of modules, could have become prohibitive.

Occasionally it seems that greater use of computers has increased our burdens. Given that the U.S. construction industry has only moved to widespread computer use in the last five or so years, many are still acclimating to its use. Manufacturers of hardware and software continue refining and improving their products at a ferocious rate, which in turn extends the acclimation period for users. Nonetheless, the trend is irreversible. Preliminary data from an on-going CII study indicates that 95 percent of the large industrial projects completed in 1990 used CADD. Remember that less than ten years ago many questioned whether CADD represented an improvement possibility. Today many harbor the same reservations about the usefulness of 3-D modelling. Data from the same on-going study shows that only ten percent of large industrial projects completed in 1990 utilized it. The project team for the modular refining unit in the UK, however, is convinced that 3-D modelling was essential in assuring proper fit-up among modules and between a module and its foundations. Moreover, the envisioned integration and sharing of project information, depicted in Figure 2, has 3D modeling with a relational database at its core. As soon as integrated project information systems 
become the norm, attainment of project objectives that appear out of reach today will become commonplace.

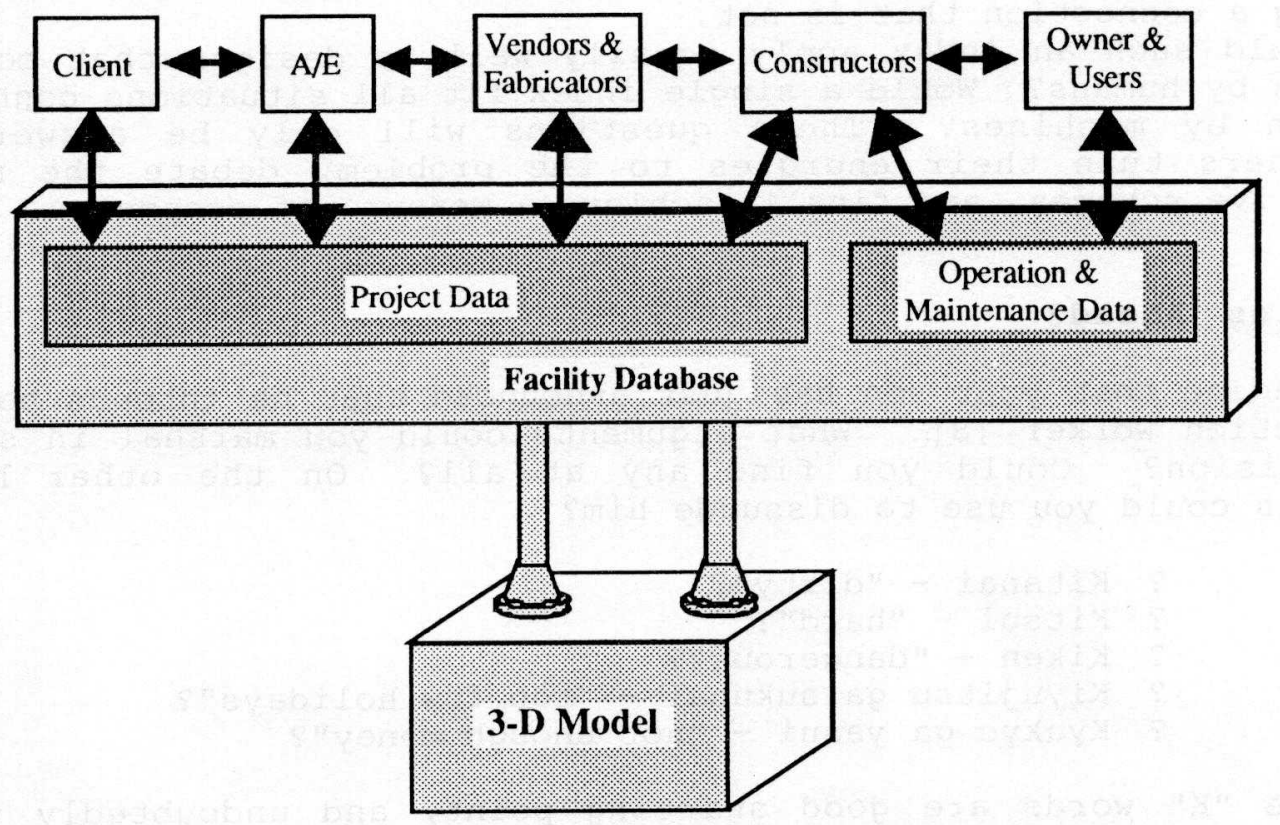

Figure 2. Schematic Facility Model

The Constructability process itself can be further automated when portions of the process, such as the "lessons learned" portion of the IPEC system, are installed in expert systems. An expert system to evaluate the applicability of modularization is currently being developed by a CII Task Force. An expert system for module optimization incorporating lessons learned from past modular projects would complement it nicely should modularization appear feasible.

Constructability is also served when innovative techniques are used during the construction phase. A device for disconnecting the load from the crane by a worker on the ground was used during construction of the chemical plant in Houston. No worker was required to ascend in a basket to disconnect the rigging or to unlatch a shackle from a precarious perch.

Many site-based applications of construction automation under investigation hold forth the promise of removing workers from dangerous situations, of making their work less taxing, or of making their work cleaner and more agreeable.

The difficulty in designing automated procedures and the machines that effect them is that the work performed by humans can be difficult to mimic with a machine. Manufacturers, who have been struggling with this problem for some time now, have decided to change the equation, to leave behind attempts to mimic human motions with machines. Instead, they prefer to alter designs to facilitate machine assembly. For example, Toshiba rates its product designs according to a "Assembly Evaluation Index." Designs score well for vertical assembly characteristics and poorly for too many screws [6, p. 175].

Those pursuing construction automation to replace workers in the field need a similar index, a "Constructability Index" to help them evaluate whether current designs are suitable for automation. Where current designs are not suitable, the designer of the automated procedure needs to suggest an alternative component design that facilitates automated construction, a design that is constructable. A good example of 
this approach is the new beam-to-column, structural steel connection from Lehigh University's Center for Large Structural Systems [7]. They believe that conventional bolting is too difficult for machines and so are pursuing a connection that is not.

Would such an index apply equally well to designs that contemplate erection by humans? Would a single index fit all situations contemplating erection by machines? These questions will only be answered after researchers turn their energies to the problem, debate the merits of alternative schemes, and finally achieve a measure of consensus.

\section{What Lies Ahead?}

Imagine that your son has just announced that he intends to become a construction worker [8]. What arguments could you marshal in support of his decision? Could you find any at all? On the other hand what arguments could you use to dissuade him?

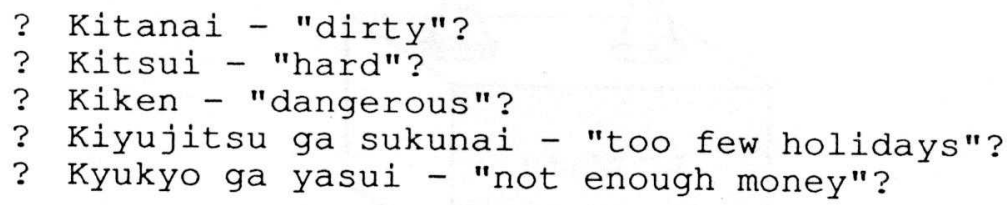

The five "K" words are good starting point, and undoubtedly you could think of several others.

Thus far, we have conspicuously omitted "too few holidays" and "not enough money" from the discussion of constructability accomplishments and automation goals. Do construction workers really have "too few holidays?" It seems that many workers now get "holidays" every time the weather is too cold or too wet or when the ground is too muddy. Too many holidays of the unpaid and unscheduled variety because of weather severely diminish a worker's overall pay and its regularity. In addition to the strains of life common to everyone, the construction worker often cannot predict his income and thus cannot bring the degree of order to his affairs that most people take for granted. The fact that construction work tends to be dirtier, harder, and more dangerous than most other jobs further balances the equation in favor of a prospective worker looking to other industries first. In light of your son's announced intention to become a construction worker you may even wonder whether he is suffering from some malady that needs a doctor's care.

The industry is well aware of its predicament and is taking steps to correct the hazards that have traditionally faced its workforce through constructability. Preliminary data from the same on-going CII study mentioned earlier shows that 56 percent of the projects completed in 1990 had formal constructability programs. As has been shown, these programs are producing good results, and the percentage of projects that have constructability programs is likely to rise as a result. A constructability program also provides a forum for introduction of innovative technologies, such as the shackle released by a worker on the ground, and can be the vehicles by which automation is transported from the laboratory to the jobsite. As automation becomes more commonplace, the effect on the workplace from constructability programs and automation could be dramatic.

Automation, however, is not a simple matter. To effectively automate, we must review designs for compatibility with automation; we need to assess our designs for automated constructability. Those who will offer the best automation schemes will also offer designs that may differ radically from those currently favored, so that automation of those designs is easier to achieve. 
As we succeed in the modularization of designs, built by robots in factories from 3-D models, and assembled in the field by methods that employ automation wherever possible, we will have made the work safer, cleaner, and less strenuous. We will also have substantially reduced the workforce required to build a project. The workforce that remains must be better educated and better motivated. The successful project will depend upon each worker's successful execution of his assignment. Companies will recognize that better-educated workers are also harder to replace and thus will pay more money and provide better benefits to retain them.

By the year 2020 we will have seen more than another quarter century of continued use and improvement of constructability concepts and more than a quarter century of development of reliable automation and appropriate designs. By then, a son's or daughter's announcement that he or she intends to become a construction worker could become much easier to support, because the " $K$ " words will have become an artifact of history.

\section{References}

1. Constructability Task Force. 1986. Constructability: A Primer, Publication 3-1. Austin: Construction Industry Institute.

2. Testolin, Gene and Steve Knisely. 1991. Constructability, Videotape VC-114. Austin: Construction Industry Institute.

3. Hoover, Dick and Rob Hunt. 1991. Fall Prevention, Videotape VC-106. Austin: Construction Industry Institute.

4. Beaumont, Mike and Ken Hamilton. Modularization, Videotape VC-109. Austin: Construction Industry Institute.

5. Russell, J. S., J. G. Gugel, and M. W. Radtke. 1992. Documented Constructability Savings for Petrochemical Facility Expansion. Working Paper. Dept. of Civil and Environmental Engineering, University of Wisconsin-Madison.

6. Schodt, F. L. 1988. Inside the Robot Kingdom. New York: Kodansha International.

7. Dorris, Virginia K. 1991. Searching for Solutions. ENR, Dec. 16, 24,25 .

8. Bryan, R. 1990. Work Force Forum, Videotape V-037. Austin: Construction Industry Institute. 